\title{
Liquid-Based Cytology in Fine-Needle Aspiration Biopsies of the Thyroid Gland
}

\author{
Guido Fadda Esther Diana Rossi \\ Division of Anatomic Pathology and Histology, 'Agostino Gemelli' School of Medicine and Hospital, \\ Università Cattolica del Sacro Cuore, Rome, Italy
}

\section{Key Words}

Thyroid nodules • Fine-needle aspiration cytology • Liquid-based cytology

\begin{abstract}
Objectives: Fine-needle aspiration biopsy is regarded as the most important diagnostic tool for thyroid lesions because of its simplicity, safety, and cost-effectiveness. However, its pivotal role in the correct characterization of the majority of nodules is impaired by the difficulties in discriminating benign from malignant follicular-patterned lesions. Study Design: Liquid-based cytology (LBC) is a semiautomated device that has recently become widely available and has gained popularity as a method of collecting and processing both gynecologic and nongynecologic cytologic specimens. It achieves a diagnostic sensitivity as accurate as conventional preparations, especially for its excellent cell preservation and lack of background which decrease the amount of inadequate diagnoses. Results: In many cases the cytologic features are similar in both methods, but the colloid film and the lymphocytic component are more easily evaluated on direct smears whereas nuclear details and colloid globules are better evaluated in LBC slides. The material stored in the preservative solution could be effectively used
\end{abstract}

for the application of immunocytochemical and molecular techniques. Conclusions: LBC-processed biopsies represent a valid alternative to conventional cytology. The possibility of applying additional techniques enhances the efficacy of the cytologic diagnosis of thyroid lesions.

Copyright $\odot 2011$ S. Karger AG, Basel

\section{Introduction}

Fine-needle aspiration biopsy (FNAB) was introduced for the first time in the USA in the 1930s, but it was only until the 1950s that it was recognized in Sweden as an invaluable diagnostic tool. Since then this method has spread worldwide because of its simplicity, safety, and possibility of repetition $[1,2]$.

The incidence and mortality of thyroid cancer do not qualify this tumor as an important public health problem, but the number of surgical lobectomies performed to assess its presence makes it a disease of economic importance. In this setting FNAB is regarded as the most accurate and cost-effective method for the selection of patients with thyroid nodules [3].

FNAB of a thyroid nodule is preferably carried out under sonographic guidance, and presently the maneu-

\section{KARGER}

Fax +41613061234 E-Mail karger@karger.ch www.karger.com
(C) 2011 S. Karger AG, Basel

0001-5547/11/0555-0389\$38.00/0

Accessible online at:

www.karger.com/acy
Correspondence to: Prof. Guido Fadda

Division of Anatomic Pathology and Histology, Catholic University of Sacred Heart

Agostino Gemelli School of Medicine and Hospital

Largo Francesco Vito, 1, IT-00168 Rome (Italy)

Tel. +39063015 4433, E-Mail guidofadda@ rm.unicatt.it 
ver is only seldom performed under manual guidance even if the lesion is palpable $[4,5]$. The procedure can be repeated safely when the smear shows low cellularity at an on-site assessment and a reliable diagnosis cannot be rendered [6]. When an on-site check is not possible and when the liquid-based cytology (LBC) technique is chosen (see below) a minimum of 2 passes is required, depending on the skill of the operator and on the characteristics of the lesion. Once the needle is withdrawn from the lesion, the material is extruded onto glass slides for a conventional smear (CS) which is fixed with $95 \%$ ethyl alcohol for the Papanicolaou stain. Alternatively, the smear may be air-dried and then stained with MayGrunwald Giemsa, which also yields excellent results in thyroid cytology.

The thin-layer or LBC technique, originally developed for application in gynecologic cervical smears, has progressively gained consensus after being applied in both nongynecologic and fine-needle aspiration cytology.

This method is based on a 2 -step procedure: (a) fixation of the totality of the material in an alcohol-based solution (methanol or ethanol, depending on the technique - see below) and (b) automated processing of the material to obtain a thin layer of representative cells. The innovation is a computer-assisted device which allows the transfer of the fixed and partially disaggregated cells onto a single slide. The 2 most common FDA-approved methods for processing the cytologic samples use an alcohol-based fixative solution. In the first method (ThinPrep2000 ${ }^{\mathrm{TM}}$; Hologic Co., Marlborough, Mass., USA), the cells are aspirated from a methanol-based solution (Cytolit ${ }^{\mathrm{TM}}$ ) and then filtered and transferred onto a positively charged slide with gentle positive pressure. In the latter method the cells are collected in an ethanol-based solution $\left(\right.$ CytoRich $\left.{ }^{\mathrm{TM}}\right)$, centrifuged twice, and then slowly sedimentated onto a poly-L-lysinated slide and eventually stained with a specific hematoxylin-eosin stain (SurePath $^{\mathrm{TM}}$; TriPath Imaging, Burlington, N.C., USA). The final result for both methods is 1 slide for each lesion where all cells are concentrated in a thin layer on the central area of the slide measuring $20 \mathrm{~mm}^{2}$ for ThinPrep and $13 \mathrm{~mm}^{2}$ for SurePath [7].

Two methods can be chosen for processing thyroid FNAB with the LBC technique: 'split sample' and 'direct to vial'. The former method requires that the aspirated material be split into 2 equal parts: the first half is smeared onto slides for CS, and the second half is submerged in a preservative solution for LBC. This method is ideal when carried out by a skilled operator; in this setting cytopathologists are generally well trained for an equal subdivi- sion of the material and they can immediately check its adequacy after staining a CS. However, most clinicians and radiologists tend to extrude the majority of the material onto the slides for CS and to save only a small, sometimes nonsignificant portion for LBC. In these cases double sampling of the lesion - the first smeared onto slides for CS and the second 'direct to vial' for LBC - is recommended even if the patient may undergo 2 or more biopsies of the same lesion with a higher risk of complications.

Although some authors are still skeptical regarding the efficacy of LBC when used alone for diagnosing thyroid lesions [8], good results have been achieved by our (and other) groups, especially in recent years. Since November 2003, the majority of the almost 19,000 FNAB carried out at the 'Agostino Gemelli' School of Medicine and Hospital of Rome have been processed by LBC alone, adopting the CS for fewer than 2,000 of them performed under manual guidance. This experience has been reported in many studies published from 2005 to date and it emphasizes the efficacy of the LBC technique for the correct preoperative diagnosis of more than 500 malignant neoplasms. In the study published in 2009 by Rossi et al. [9], 3 parameters of efficacy (inadequacy, indeterminacy, and malignancy rates) were evaluated in a series of 10,360 thyroid FNAB. In that investigation the use of ThinPrep alone was as effective as CS in decreasing both inadequate and indeterminate cases whereas the majority of problems occurred when LBC and CS were simultaneously adopted (split sample, see above) [9]. These problems accounted for a high rate of inadequate and falsenegative diagnoses and were also reported in many studies published in different countries [10-14]. In series where the direct-to-vial method is used, and all of the cellular material is therefore submitted for cytologic analysis, the average cellularity is generally higher than with the split-sample method and the rates of inadequacy and false positivity decrease significantly $[9,13,15,16]$. Regarding the results of Geers and Bourgain [17] using the SurePath method, these authors did not achieve good results in terms of the inadequacy rate but there might be some reasons related to the technical differences between ThinPrep and SurePath (see Inadequate Smears). Nevertheless, they claimed a significant reduction of the falsenegative diagnoses.

The material remaining in the vial after cytologic diagnosis can be used for the application of ancillary techniques such as immunocytochemistry (ICC), flow cytometry, and molecular biology because the LBC method enables the storage of a variable amount of cells for up to 6 months after the biopsy [18-22]. 


\section{Inadequate Smears}

In the best interest of the patient, the cytopathologist must receive an adequate biopsy specimen to make a meaningful cytopathologic evaluation and a correct diagnosis. The final cytologic specimen must be adequate in terms of cellularity and satisfactory in terms of quality (thickness, fixation, and staining).

An FNAB is defined as unsatisfactory when fixation, smearing, or staining artifacts impair the interpretation of the final slide. A slide is nonrepresentative when the cellularity does not represent the true components of the lesion (e.g. insufficient amount of follicular cells) [23]. In the first instance the inadequacy of the sampling could be attributed to an incorrect technique, and in the latter the characteristics of the lesion do not allow a definitive cytologic diagnosis [24-26]. In both CS and LBC the adequacy criteria are met when at least 6 clusters of 10-20 well-preserved cells are observed [24-28]. When an LBC slide does not contain an adequate number of cells, a second slide can be prepared with the residual cells to meet the adequacy criteria [29]. In the latter scenario up to $18 \%$ of cases, diagnosed as inadequate after the first slide, can be reclassified as adequate after the second slide and this result is more significant than the data by Hasteh et al. [30] who dismiss as expensive and useless the preparation of a second ThinPrep slide. The LBC ThinPrep-processed slides may show a few ill-preserved cells at the periphery of the circle because transfer from the preservative solution to the specific slide requires positive pressure which may give rise to cellular artifacts. SurePath, according to Geers and Bourgain [17], yields an inadequacy rate of $25 \%$ in thyroid aspiration cytology. This result can probably be attributed to the low sedimentation rate of the colloid droplets which might hinder their inclusion in the final slide [17].

Cystic lesions are most commonly responsible of nonrepresentative cases [31,32]. A thyroid cyst is seldom a true pseudocystic lesion (without a wall of follicular cells); more frequently it represents cystic or hemorrhagic regression of a nodule which might turn out to be benign or malignant after repeated samplings. LBC slides show many hemosiderin-laden histiocytes with very few clusters of follicular cells and colloid droplets (see below). A conclusive diagnosis is based on the morphologic features of the follicular cells, if their amount meets the adequacy criteria, and on the number of colloid droplets. Otherwise, the final diagnosis is nonrepresentative. In our studies $[9,15]$ cystic/hemorrhagic lesions accounted for about $7 \%$ of all cases.

LBC in Thyroid Biopsies
When an FNAB of a cystic nodule with a solid component is repeatedly nonrepresentative, surgical excision of the nodule may be considered to avoid the possibility of a malignant lesion (between 8 and 19\% of cases according to literature) $[7,27,28,31,32]$.

\section{Benign Diseases of the Thyroid}

\section{Goiter}

FNAB of nodules in goiters span a wide spectrum of morphologic changes reflecting different stages of the disease: early follicular hyperplasia, cycles of involution/ regeneration, and nodule formation. Secondary changes such as oxyphilic metaplasia, recent and old hemorrhage, cystic degeneration, necrosis, granulation tissue, fibrosis, and calcification may occur in all of these stages.

Two critical points differentiate LBC from CS. First, the cells in each slide are a monolayered representative sample of all of the material collected in the vial. The whole cellularity is seldom collected in a single LBC slide; thus, a variable number of them is stored in the preservative solution to be used for additional investigations. Second, the automated process causes some changes in both cellular and background morphology (table 1). One of the most important changes occurring in LBC compared to CS slides is the appearance of the colloid which is fragmented during the filtering procedure. Therefore, this substance is observed as small droplets in the background of benign nodules: the higher the number of these colloid droplets, the higher the likelihood of benignancy of the nodule $[15,20,34]$. Thus, the LBC evaluation of the amount of colloid is quantitative whereas in CS the presence of colloid in the background usually does not require quantitation (fig. 1). The lack of watery colloid, which has been considered a major problem by some authors $[8,12-16]$, can be considered a minor diagnostic detail provided this substance is accurately sought instead of being only roughly evaluated at a lower magnification. Colloid droplets can sometimes be detected mixed with hemorrhagic debris and hemosiderin-laden histiocytes within a cystic lesion (see above). Unlike CS, the LBC picture may be safely interpreted, in the presence of a small amount of typical follicular cells, as goiter with hemorrhagic changes $[33,35]$.

\section{Thyroiditis}

A cytologic diagnosis of thyroiditis can be very puzzling at times, and the clinical and immunologic findings must be considered $[36,37]$. A clinical picture of a tender 
Table 1. Comparison between the features of conventional cytology and LBC

\begin{tabular}{|c|c|c|c|}
\hline Diagnosis & CS & LBC & $\begin{array}{l}\text { Histologic } \\
\text { correspondence }\end{array}$ \\
\hline \multicolumn{4}{|c|}{ Nonneoplastic lesions } \\
\hline $\begin{array}{l}\text { Colloid } \\
\text { nodule }\end{array}$ & $\begin{array}{l}\text { Abundant and clumped colloid; large } \\
\text { sheets of small thyrocytes with 'hyalinized } \\
\text { stroma'; foamy 'colloidophagic' histiocytes }\end{array}$ & $\begin{array}{l}\text { Clusters of small monomorphic thyrocytes } \\
\text { with clear, sometimes 'granular' } \\
\text { cytoplasms; small clumps of dense colloid } \\
\text { (colloid globules); foamy 'colloidophagic' } \\
\text { histiocytes }\end{array}$ & $\begin{array}{l}\text { Diffuse or nodular goiter; } \\
\text { macrofollicular } \\
\text { adenomatous nodule in a } \\
\text { goiter }\end{array}$ \\
\hline Thyroiditis & $\begin{array}{l}\text { Inflammatory cells (mostly mature } \\
\text { lymphocytes) in the background; fragments } \\
\text { of reticular tissue with epithelioid } \\
\text { histiocytes; small clusters of thyrocytes } \\
\text { sometimes with oxyphilic metaplasia; scant } \\
\text { colloid; plurinucleated histiocytes }\end{array}$ & $\begin{array}{l}\text { Small clusters of thyrocytes or oxyphilic } \\
\text { cells mixed with lymphohistiocytes } \\
\text { (lymphoepithelial clusters); the same cells } \\
\text { are present in the background; few droplets } \\
\text { of colloid; large plurinucleated histiocytes }\end{array}$ & $\begin{array}{l}\text { Granulomatous De } \\
\text { Quervain's thyroiditis; } \\
\text { lymphocytic 'Hashimoto } \\
\text { type' thyroiditis }\end{array}$ \\
\hline
\end{tabular}

\section{Follicular lesions}

FN Scant colloid; microfollicles or small clusters of medium-sized thyrocytes, sometimes with slight nuclear pleomorphism (hyperfunction) and rounded nuclei; fibrovascular tissue; hemorrhage with hemosiderin-laden histiocytes

OFN Scant colloid; sheets or clusters of oxyphilic cells; hemorrhage; scattered inflammatory cells and reticular tissue in the background may be seen in thyroiditis
Small clusters of medium-sized thyrocytes with pleomorphic nuclei, generally with regular outlines; fibrin flakes; scant or no colloid droplets; hemosiderin-laden histiocytes
Adenomatous nodule; follicular adenoma; minimally invasive follicular carcinoma; FVPC
Small aggregates of oxyphilic cells with brilliant cytoplasmic granules and large hyperchromatic pleomorphic nuclei; fibrous tissue; scant colloid globules (with inflammatory cells; see Thyroiditis)
Oxyphilic adenomatous nodule; oxyphilic neoplasm; oxyphilic hyperplastic nodule in thyroiditis

\section{Suspicious for carcinoma}

Follicular Absent colloid; small clusters or lesion microfollicles of medium-to-large-sized suspicious for PC thyrocytes with moderate nuclear pleomorphism, irregular nuclear membrane, clearing, and grooves (no pseudoinclusions or papillae), and often oxyphilic cytoplasms; hemorrhage; fibrovascular tissue
Small clusters of medium-sized thyrocytes (see FN) mixed with scattered aggregates of large cells with pleomorphic nuclei, clear chromatin, and irregular nuclear outlines; no papillae or nuclear pseudoinclusions; fragments of fibrous tissue; if prominent nucleoli: hyperplastic nodule (Graves' disease)

\section{Malignant neoplasms}

PC Absent colloid; large irregular sheets or papillae lined by large thyrocytes with severe nuclear pleomorphism and irregularities, with pseudoinclusions and grooves; hemorrhage; fibrovascular tissue
Aggregates of thyrocytes with large and elongated nuclei with grooves and focal pseudoinclusions; plurinucleated giant cells; fibrin filaments; iron-laden histiocytes; small and thin papillae (uncommon)

\footnotetext{
Medullary carcinoma

Small clusters of cells with round or ovoid slightly pleomorphic nuclei eccentrically disposed ('plasmacytoid cells'); fragments of hyaline material; scant colloid; calcitonin and CEA positivity
}

FVPC; 'toxic' or hyperplastic adenoma; follicular carcinoma. The frozen-section examination is suggested
Isolated cells with eccentrically disposed ('plasmacytoid cells') or cylinder-shaped round or ovoid slightly pleomorphic nuclei; calcitonin and CEA positivity
PC

Medullary carcinoma

OFN = Oxyphilic follicular neoplasm; FVPC $=$ follicular variant of papillary carcinoma. 


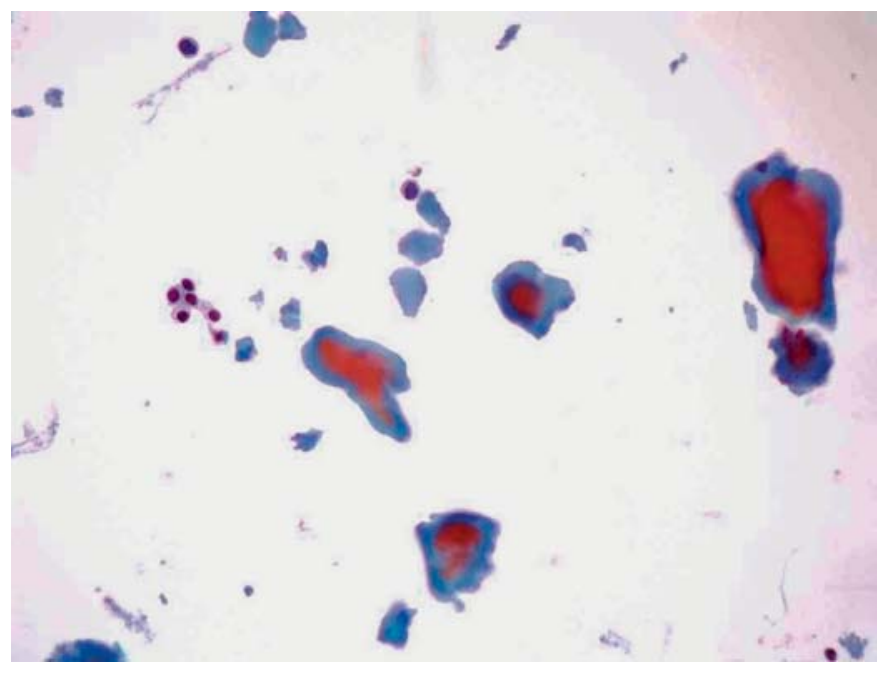

Fig. 1. Small droplets of amphophilic colloid are surrounded by clusters of small thyrocytes in a colloid goiter (Papanicolaou, ThinPrep, ×500).

gland with small inconspicuous nodules whose cytology shows mature lymphocytes, plasma cells, and scattered giant cells is likely to be a granulomatous thyroiditis (De Quervain's).

The LBC picture of lymphocytic thyroiditis is similar to CS with one exception: in a CAT the amount of lymphocytes in the background of the slide can be higher than normal because of the spinning of the material before the automated process. When a CAT is suspected, the detection of lymphoepithelial clusters on an inflammatory background is the pivotal clue for the diagnosis (fig. 2) [16]. This setting represents the opposite of goiter: LBC diagnosis of thyroiditis requires identification of the lymphoepithelial clusters, and the simple detection of lymphohistiocytic cells in the background of the slide does not warrant a diagnosis of thyroiditis. According to the literature, the LBC diagnosis of thyroiditis is reliable [8]. Oxyphilic hyperplastic nodules in a CAT should not be sur-gically removed because they represent the functional replacement of parenchyma infiltrated by the inflammatory cells. The occurrence of either an oxyphilic carcinoma or a non-Hodgkin primary lymphoma within a CAT is exceedingly uncommon compared to the frequency of papillary carcinoma (PC) which can easily be detected by cytology. Thus, identification of lymphoepithelial clusters, mostly when made up of oxyphilic cells, virtually rules out an oxyphilic neoplasm and warrants a simple follow-up for the patient.

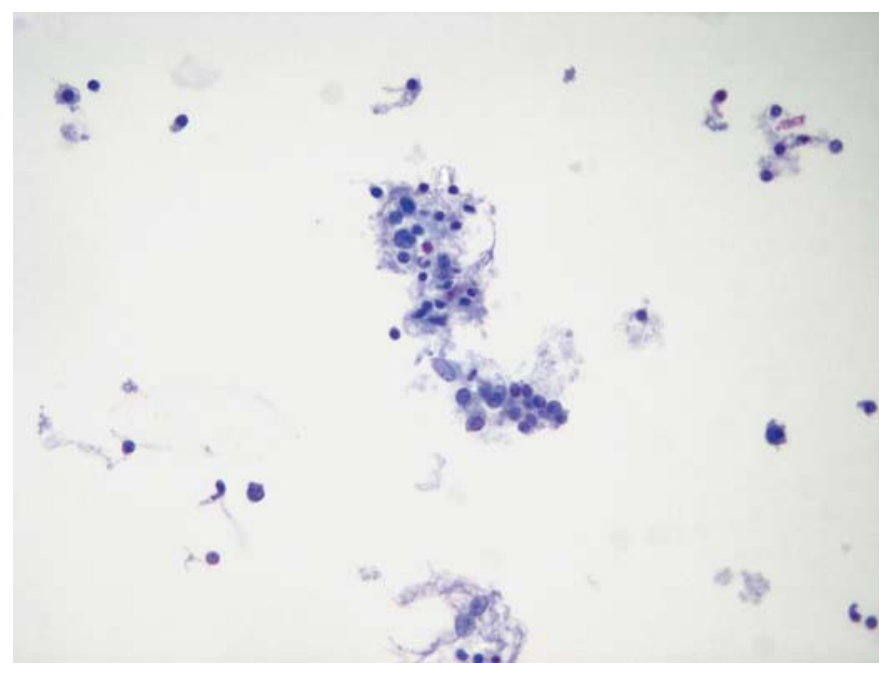

Fig. 2. Lymphoepithelial cluster made up of small lymphocytes, histiocytes, and larger thyrocytes in a chronic autoimmune thyroiditis (Papanicolaou, ThinPrep, $\times 500$ ).

\section{Toxic Goiter}

FNAB is not usually the first choice in cases of toxic goiter unless a 'cold' lesion is detected during a scan. However, some cases in which the cytopathologist faces this diagnosis may occur: (a) a preclinical hyperfunctioning nodule, where a decrease of the circulating TSH is the only clinical sign; (b) a 'cold' nodule within a toxic goiter, where the sampled lesion can be a hyperplastic nodule inhibited by the surrounding toxic goiter; (c) a rapidly growing toxic nodule during suppressive therapy, and (d) a hyperplastic nodule in a CAT. The cytologic picture of a toxic nodule is that of a follicular neoplasm (FN) showing microfollicles layered by medium-sized thyrocytes with distinctive vacuolated cytoplasms ('fire-flare' or 'flame cells'; fig. 3) [38, 39]. The colloid in the background is scant and focal nuclear pleomorphism may be detected in a longstanding goiter. Scattered lymphoid cells may be present in a smear of a toxic goiter and, on the other hand, cells with features of hyperfunction may appear in an otherwise obvious colloid nodule or in thyroiditis.

The hyperfunctioning features described above are important in the decision for follow-up rather than surgery in a single follicular-structured nodule [38]. Since the malignant risk in a toxic nodule is low the detection of hyperfunctioning thyrocytes rules out this possibility, avoiding an unnecessary thyroidectomy.

Acta Cytologica 2011;55:389-400 


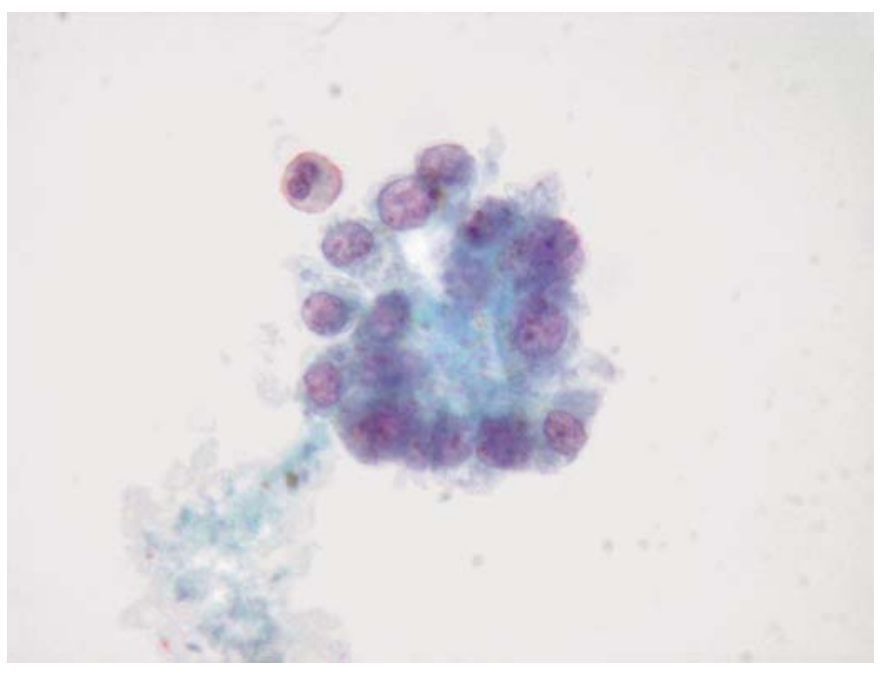

Fig. 3. Microfollicular cluster of medium-sized thyrocytes with slightly pleomorphic nuclei and vacuolated cytoplasms (flame cells) in a toxic nodule (Papanicolaou, ThinPrep, $\times 1,000)$.

\section{Follicular Lesions}

There are very few differences in the cytologic pictures of FN in LBC compared to CS. This diagnosis is based on the identification of microfollicles made up of mediumsized follicular cells in a background with scant colloid. The amount and morphology of the follicular cells allow the inclusion of an individual lesion in one of the categories that have been recently devised in Europe and in the USA. There are 3 possible scenarios:

(1) The lesion is highly cellulated but the cells are monomorphous with occasional enlarged nuclei. This lesion may correspond to the cellular adenomatous nodule of DeMay and is usually included in the nonneoplastic category of European classifications (Thy 2 of the BTA classification and TIR 2 of the Italian classification) [31, 40]. On the other hand, the Bethesda classification has established a different category for this picture which is defined as 'a follicular lesion of undetermined significance' or 'atypical cells of undetermined significance'. The difference between these two categories resides in the different risk of malignant occurrence; in the American classification it is in the range of 5-15\% (mostly follicular carcinoma) whereas in the European systems it is closer to nonneoplastic lesions.

(2) The lesion is mostly follicular structured and is made up of medium-sized thyrocytes with rounded nuclei and central nucleolus (follicular neoplasm or suspi-

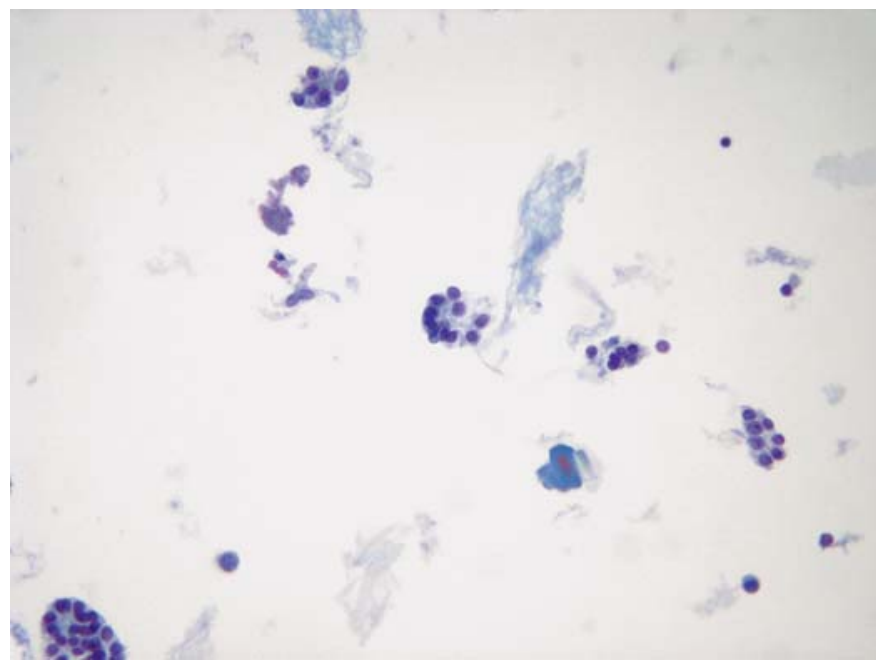

Fig. 4. Small microfollicular clusters of medium-sized thyrocytes with rounded nuclei in an FN (Papanicolaou, ThinPrep, $\times 400)$.

cious for follicular neoplasm; fig. 4). In this case there is almost complete agreement among the different classification systems in terms of malignancy risk (between 20 and $30 \%)$. The action, although still debated in the literature, results in surgical removal of the lesion after a collegial discussion. The same diagnostic criteria and therapeutic action apply to the FN composed mostly of oxyphilic (or Hürthle) cells (see below). At histology an FN may correspond to a follicular adenoma or an adenomatous nodule in a goiter ( $70-80 \%$ of cases) but a follicular carcinoma or a follicular variant of PC cannot be ruled out based only on morphology.

(3) The lesion is follicular structured and composed of follicular cells with elongated and clear nuclei (sometimes with grooves and peripheral nucleoli) (fig. 5a). Papillae, psammomatous bodies, or nuclear pseudoinclusions are not identified. These cases are included in the category of suspicious for PC which bears a risk of malignancy ranging between 50 and $70 \%$. This category warrants surgical removal of the nodule as a follicular variant of PC is very likely to be found upon histologic examination (more than $90 \%$ of cases).

LBC pictures of these microfollicular-patterned lesions allow a more thorough evaluation of the nuclear details of the follicular cells because the background is devoid of blood clots and fibrin.

Another advantage of the LBC technique over CS in the diagnosis of follicular lesions is the possibility of ap- 

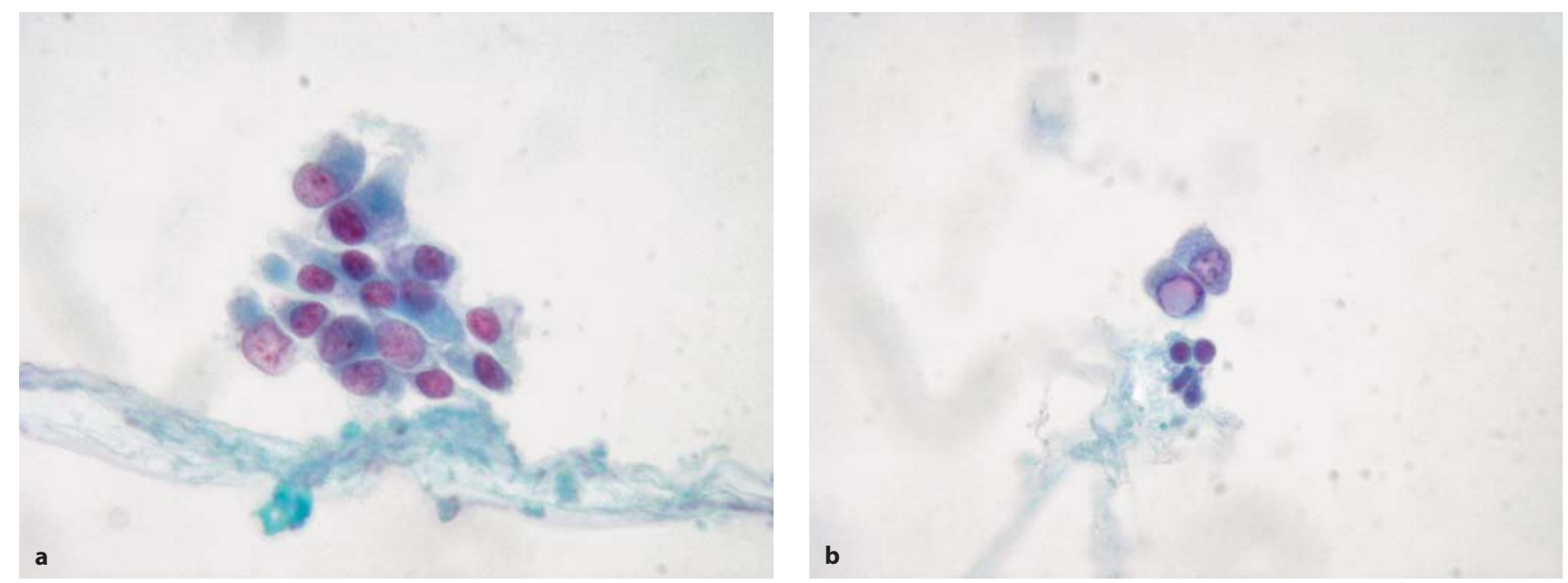

Fig. 5. a Group of thyrocytes showing nuclear elongation and clearing and irregularity of the nuclear membrane outline, suspicious for carcinoma (Papanicolaou, ThinPrep, $\times 1,000$ ). b Clear pseudoinclusion ('Orphan Annie's eye') centered in the nucleus for the diagnosis of PC (Papanicolaou, ThinPrep, $\times 1,000$ ).

plying additional investigation methods (ICC, flow cytometry, and molecular biology). These techniques, especially ICC and molecular biology, are particularly helpful in refining the diagnosis of follicular lesion and can be applied to the cells left in the vial which are safely stored at room temperature for up to 6 months after the sampling of the lesion (see above).

\section{Oxyphilic (Hürthle Cell) Lesions}

The FNAB of an oxyphilic lesion is categorized as an 'oxyphilic or Hürthle cell neoplasm' when follicles made up of more than $80 \%$ oxyphilic cells are identified. The colloid amount may be scant (but is sometimes abundant), and features of old hemorrhage (hemosiderin-laden histiocytes) may coexist. Both fire-flare cells (detected in hyperfunctioning lesions or in juvenile thyroiditis see above) and small thyrocytes (more than $20 \%$ of the cellular component) suggest a benign lesion with an oxyphilic component. Unlike their follicular counterpart, oxyphilic cells may feature nuclear enlargement and pleomorphism either in benign neoplasms or even in hyperplastic lesions. The most paradigmatic case is represented by hyperplastic nodules in CAT which may show a striking nuclear pleomorphism of the oxyphilic component $[1,2,41-49]$. Some authors have attempted to correlate the atypia of oxyphilic cells (and some other fea- tures such as transgressing vessels) with the risk of malignancy, but their results are still debatable $[47,49]$. Thus, a lesion made up of oxyphilic cells should be included in the FN category (Thy 3 of the BTA classification and TIR 3 of the Italian classification) if more than $80 \%$ of the cells are oxyphilic. Otherwise, it should be included in the nonneoplastic category as it might be either a hyperplastic nodule in a CAT or a oxyphilic component of a goiter.

\section{Thyroid Malignant Neoplasms}

The cytologic diagnosis of thyroid malignancy does not differ substantially in LBC preparations with respect to CS. As mentioned before, the clear background facilitates the identification and characterization of the cellular details distinctive of each neoplasm.

The most important malignant tumor which should be appropriately identified is papillary carcinoma. LBC diagnosis of PC is straightforward when the nuclear pseudoinclusions (major criterion) are detected even within tridimensional clusters of cells with nuclear elongation and clearing (minor criteria - see previous paragraph; fig. 5b) [50, 51]. Papillary structures and psammoma bodies are seldom identified. The lack of fibrin clots and red blood cells in the background enables the identification of the distinctive PC cells within a hemorrhagic or cystic degeneration of the tumor. In earlier re- 

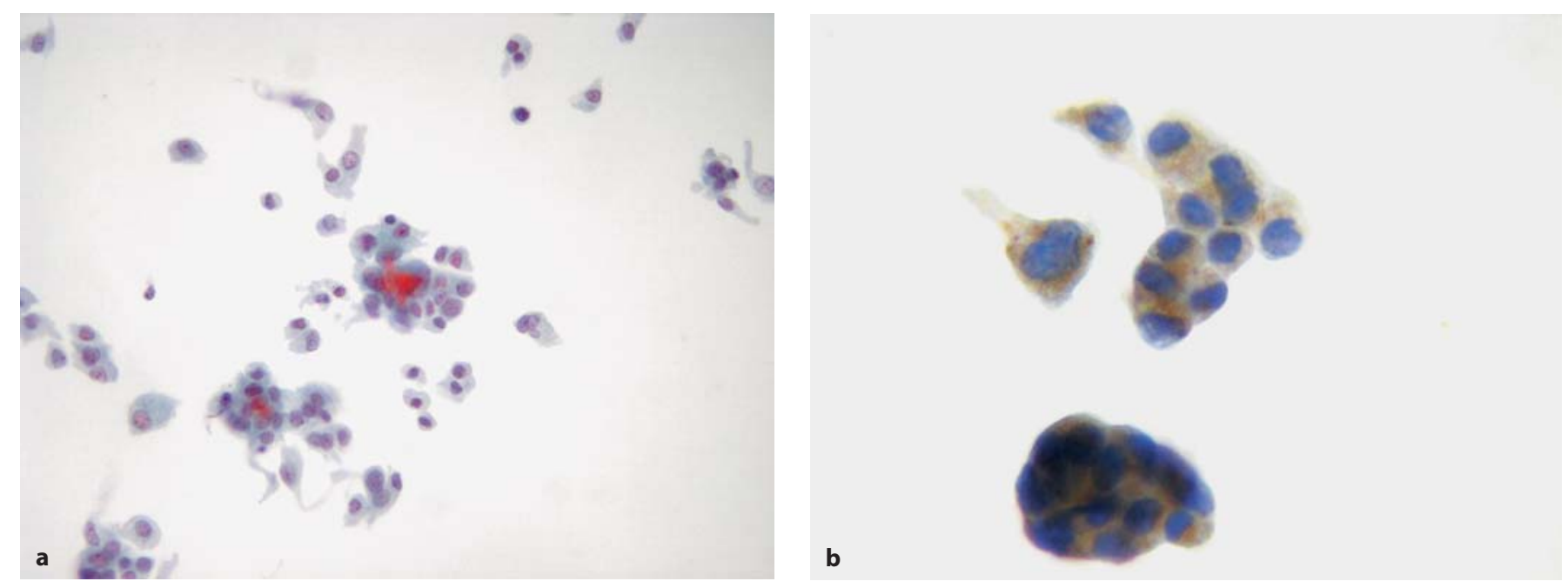

Fig. 6. a Neoplastic parafollicular cells showing plasmacytoid and spindle shapes (Papanicolaou, ThinPrep, $\times 500)$. $\mathbf{b}$ The same cells are strongly positive for calcitonin, confirming the diagnosis of medullary carcinoma (ABC, ThinPrep, $\times 1,000)$.

ports, the difficulty in detecting the distinctive nuclear features of PC was one of the most important objections against adoption of the $\mathrm{LBC}$ technique in thyroid cytology. However, the most recent investigations have somewhat corrected those data and emphasized $[9,10,15,17$, $52,54]$ that accurate evaluation of both the major and the minor diagnostic criteria of PC plays a pivotal role in the preoperative characterization of PC. This diagnostic efficacy includes the diffuse sclerosing and tall cell variants of PC which warrant an aggressive surgical approach.

Medullary thyroid carcinoma (MTC) is a difficult diagnosis in thyroid cytology. It usually relies on the identification of a double population of both plasmacytoid and spindle cells with variable nuclear pleomorphisms (fig. 6a). The amounts of these components can be variable in a way that an MTC may alternatively look like a plasmacytoma or a mesenchymal neoplasm. As the cytologic diagnosis of MTC is very important in order to establish the most appropriate surgical strategy, the LBC technique offers the opportunity to identify the presence of calcitonin in neoplastic cells (fig. 6b). To avoid falsepositive results, the negativity for thyroglobulin of the neoplastic parafollicular cells needs to be confirmed [55].

Anaplastic thyroid carcinoma (ATC) is an uncommon finding in thyroid cytology as this tumor presents a rapid growth which frustrates attempts to plan a surgical strategy. The LBC picture of ATC usually shows a background of necrotic debris and fibrovascular fragments with small clusters of large round or spindle cells with pleomorphic nuclei and prominent nucleoli. Aggregation of these cells and their large cytoplasms helps to distinguish this neoplasm from a large cell non-Hodgkin malignant lymphoma, which represents, from a clinical and morphologic viewpoint, the most important differential diagnosis. In many cases the cellularity may be exceedingly scant so that the neoplastic cells can be misdiagnosed as histiocytes. Immunostains for cytokeratins may be useful to confirm the epithelial origin of these cells which usually do not express thyroglobulin or TTF-1.

LBC diagnosis of the large cell variant of malignant non-Hodgkin lymphoma, which must be distinguished from ATC (see above), is usually simple. The correct characterization of this tumor, which prevents a surgical approach, relies also on the immunocytochemical expression of LCA, CD20, bcl-6, and other lymphocytic antigens. Insular thyroid carcinoma is a very rare occurrence and shows a solid pattern made up of small thyrocytes with dark nuclei. Small flecks of necrotic debris may sometimes be seen in the background. Metastatic carcinoma to the thyroid gland may occasionally present as a single nodule mimicking a primary tumor. In a background of necrotic debris or hemorrhagic material, clusters of neoplastic cells with features of adenocarcinoma or squamous cell carcinoma are detected. The lung, breast, kidney, large bowel, and larynx are the most common primary sites [56]. 


\section{Special Techniques}

\section{Immunocytochemistry}

Immunohistochemistry was introduced in the early 1970s for specific use directed toward the definition of the nature of lesions and then became an invaluable diagnostic tool in both surgical pathology and cytopathology. The antibodies utilized include those directed at cytoplasmic and membrane-bound antigens as well as nuclear and matrix antigenic sites.

ICC plays an important role in the differential diagnosis between follicular and C cell-derived neoplasms and in the identification of primary or metastatic thyroid neoplasms (e.g. malignant lymphoma).

One of the most interesting insights into the role of ICC in thyroid neoplasms is the evaluation of the markers of malignancy which may distinguish malignant from benign lesions regardless of the presence of capsular or vascular invasion.

The popularity and usefulness of the technique is reflected by the large number of papers over the last 15 years. The majority of this information is synthesized in a recent paper by Colasacco et al. [57] in which the authors analyzed a total of 100 journal articles dealing with immunocytochemical stains on diagnostic cytology.

Immunocytochemical staining may be carried out on cells stored in preservative solution by preparing an appropriate number of additional slides. The use of ICC on LBC yields excellent results with most immunoreagents in terms of the staining pattern, intensity of the reaction, and the smaller amount of reagent due to the clear background and smaller size of the LBC slide [58].

The quality of the immunocytochemical reaction on thin-layer preparations, as far as morphologic details and purity of background are concerned, is much better than CS.

In routine practice, only the concordance of a panel should be considered in the diagnosis of thyroid nodules, especially in cases of follicular lesions. The use of more than one immunomarker is a further guarantee of a correct diagnostic approach, especially when a concordant result is expressed by the cells [15].

There have been only few experiences reported in the literature dealing with ICC applied to LBC. Leung et al. [59] reported satisfactory results with ICC applied in LBC slides from different body sites, except from lymphoma markers. Dabbs et al. [60] showed that ICC in LBC from a variety of neoplastic and nonneoplastic samples resulted in greater intensity and distribution of proper staining compared with conventional cytology.

LBC in Thyroid Biopsies
The studies of our group have demonstrated the possibility of applying ICC to diagnostic thyroid cytology with excellent results not only for the mutual distinction of malignant neoplasms $[15,56]$ but also in the differential diagnosis between benign and malignant FN [20].

However, based on the data in the literature, no 'magic single marker' may unmistakably distinguish benign from malignant follicular-patterned neoplasms [61].

In thyroid literature, HBME-1, Galectin-3, and RET proto-oncogene have shown the best specificity and sensitivity in discriminating benign differentiated tumors from malignant ones. These data emerged from one of the papers of our group in which the combination of nuclear pleomorphism and positivity of the antibody panel resulted in a slight increase in the specificity and diagnostic accuracy of FNAB (75 and 89\% respectively), but this improvement became quite significant when oxyphilic neoplasms, showing a distinctive cytologic picture, were excluded.

\section{Molecular Techniques}

To also contribute to this purpose, recent advances in the molecular genetics of thyroid cancer are being applied for the development of new diagnostic markers for FNA samples in an attempt to differentiate benign thyroid nodules from malignant ones [62-64]. PC, the most common thyroid malignancy, may carry BRAF, RET/ PTC, or RAS mutations [65-67]. These mutually exclusive somatic mutations are found in more than $70 \%$ of PC, and some of them are associated with more aggressive tumor behavior. Several studies have demonstrated the feasibility of detecting BRAF, RET/PTC, or RAS mutations in thyroid FNA samples and have shown that this may improve the cytologic diagnosis [67-69].

For this reason, a great number of studies have addressed the possible use of molecular tests for FNA samples in order to improve the accuracy of the cytologic diagnosis of thyroid nodules. Some groups have explored the diagnostic role of BRAF mutations with prospective and retrospective studies which evidenced that all BRAFpositive FNA samples yielded PC at histology [70].

A recent paper by Nikiforov et al. [65] emphasized the diagnostic utility of molecular testing for a panel of molecular mutations consisting of BRAF, RAS, RET/PTC, and PAX-PPAR $\gamma$ in 480 FNA samples from thyroid nodules which were prospectively tested and yielded 32 mutations with 31 malignant surgical diagnoses and only 1 case of follicular adenoma [66].

The possible diagnostic usefulness of molecular markers is reflected in the last guidelines published by the

Acta Cytologica 2011;55:389-400 
American Thyroid Association. These guidelines indicate that the use of molecular markers such as BRAF, RAS, RET/PTC, and PAX8-PPAR $\gamma$ may be considered (although with a low recommendation rate) for patients with indeterminate FNA cytology to help guide their clinical management. In fact, BRAF mutations correlate with aggressive tumor characteristics such as extrathyroidal extension, advanced tumor stage at presentation, and lymph node or distant metastases as in the review by Xing [63, 71-75].

LBC can offer the possibility of molecular testing for common somatic mutations in thyroid FNAB as the nucleic acids are stable in the preservative solution for up to 6 months after sampling. In some cases the material can also be used for the immunocytochemical evaluation of HBME-1 and Galectin-3 expression which represents a helpful investigation in discriminating low and high malignant FN. In this setting, the future possibility of a guideline encompassing the combined use of ICC and molecular tests for supplementing the morphologic diagnosis could be the starting point for a complete preoperative assessment of thyroid lesions.
As shown in our preliminary study the evaluation of BRAF positivity could be of prognostic value for the prediction of nodal metastases in the central neck compartment [76].

\section{Conclusions}

The LBC method applied to the diagnosis of thyroid lesions represents, when the cytopathologist is skilled in thyroid cytology and is aware of the morphologic changes in respect to CS, a powerful diagnostic tool. Its use reduces the number of nondiagnostic (both inadequate and artifactual) and indeterminate cases without impairing the ability to detect the distinctive features of carcinoma. Storage of a variable amount of well-preserved cells allows the application of immunocytochemical and molecular techniques which dramatically improve the efficacy of the morphologic diagnosis.

\section{References}

1 Fadda G, LiVolsi VA: Histology and aspiration cytology of benign thyroid diseases (in Italian). Rays 1999;24:182-196.

2 Galera-Davidson H, Gonzalez-Campora R: Thyroid; in Bibbo M, Wilbur D (eds): Comprehensive Cytopathology, ed 3. Philadelphia, Saunders Elsevier, 2008, pp 633-670.

-3 Gharib H, Goellner JR, Johnson DA: Fineneedle aspiration cytology of the thyroid: a 12-year experience with 11,000 biopsies. Clin Lab Med 1993;13:699-709.

-4 Danese D, Sciacchitano S, Farsetti A, Andreoli M, Pontecorvi A: Diagnostic accuracy of conventional versus sonography-guided fine-needle aspiration biopsy of thyroid nodules. Thyroid 1998;8:15-21.

-5 Papini E, Guglielmi R, Bianchini A, Crescenzi A, Taccogna S, Nardi F, Panunzi C, Rinaldi R, Toscano V, Pacella CM: Risk of malignancy in nonpalpable thyroid nodules: predictive value of ultrasound and colorDoppler features. J Clin Endocrinol Metab 2002;87:1941-1946.

-6 Redman R, Zalaznick H, Mazzaferri EL, Massoll NA: The impact of assessing specimen adequacy and number of needle passes for fine-needle aspiration biopsy of thyroid nodules. Thyroid 2006;16:55-60.

7 Rossi ED, Fadda G: Thin-layer liquid-based preparation of exfoliative non-gynaecologic and fine-needle aspiration biopsy cytology. Diagn Histopathol 2008; 14:563-570.
-8 Duncan LD, Forrest L, Law WM, et al: Evaluation of thyroid needle aspiration cytology: can ThinPrep be used exclusively to appropriately triage patients having a thyroid nodule? Diagn Cytopathol 2011;39:341-348.

\9 Rossi ED, Raffaelli M, Zannoni GF, Pontecorvi $\mathrm{A}$, Mulè $\mathrm{A}$, Callà $\mathrm{C}$, Lombardi $\mathrm{CP}$, Fadda G: Diagnostic efficacy of conventional as compared to liquid-based cytology in thyroid lesions: evaluation of 10,360 fine needle aspiration cytology cases. Acta Cytol 2009; 53:659-666.

10 Lee KR, Papillo JL, St John T, Eyerer GJ: Evaluation of the ThinPrep processor for fine needle aspiration specimens. Acta Cytol 1996;40:895-899.

11 Biscotti CV, Hollow JA, Toddy SM, Easley KA: Thin prep versus conventional smear cytological preparations in the analysis of thyroid fine-needle aspiration specimens. Am J Clin Pathol 1995;104:150-153.

12 Poller DN, Ibrahim AK, Cummings MH, Mikel JJ, Boote D, Perry M: Fine-needle aspiration of the thyroid. Cancer 2000;90:239244.

13 Linder J: Recent advances in thin-layer cytology. Diagn Cytopathol 1998;18:24-32.

14 Frost AR, Sidaway MK, Ferfelli M, Tabbara SO, Bronner NA, Brosky KR, Sherman ME: Utility of thin-layer preparations in thyroid fine-needle aspiration. Cancer 1998;84:1725 .
15 Fadda G, Rossi ED, Raffaelli M, Mulè A, Pontecorvi A, Miraglia A, Lombardi CP, Vecchio FM: Fine-needle aspiration biopsy of thyroid lesions processed by thin-layer cytology: one-year institutional experience with histologic correlation. Thyroid 2006;16:975-981.

16 Cochand-Priollet B, Prat JJ, Polivka M, Thienpont L, Dahan H, Wassef M, Guillausseau PJ: Thyroid fine needle aspiration: the morphological features on ThinPrep slide preparations - eighty cases with histological control. Cytopathology 2003;14:343-349.

17 Geers AJ, Bourgain C: Liquid-based FNAC of the thyroid: a 4-year survey with SurePath. Cancer Cytopathol 2011;119:58-67.

18 Bishop-Pitman M, Abele J, Ali SZ, Duick D, Elsheikh TM, Brooke JR, Powers CN, Randolph G, Renshaw A, Scoutt L: Techniques for thyroid FNA: a synopsis of the National Cancer Institute Thyroid Fine-Needle Aspiration State of the Science Conference. Diagn Cytopathol 2008;36:407-424.

19 Saleh HA, Hammoud J, Zakaria R, Khan AZ: Comparison of Thin-Prep and cell block preparation for the evaluation of thyroid epithelial lesions on fine needle aspiration biopsy. Cytojournal 2008;25:3.

20 Rossi ED, Raffaelli M, Minimo C, Mule A, Lombardi CP, Vecchio FM, Fadda G: Immunocytochemical evaluation of thyroid neoplasms on thin-layer smears from fine-needle aspiration biopsies. Cancer 2005;105:87-95. 
21 Gharib H: Changing trends in thyroid practice: understanding nodular thyroid disease. Endocr Pract 2004;10:31-39.

-22 Yassa L, Cibas ES, Benson CB, Frates MC, Doubilet PM, Gawande AA, Moore FD, Kim BW, Nosé V, Marqusee E, Larsen PR, Alexander EK: Long-term assessment of a multidisciplinary approach to thyroid nodule diagnostic evaluation. Cancer 2007;111:508516.

23 Haider AS, Rakha EA, Dunkley C, Zaitoun AM: The impact of using defined criteria for adequacy of fine needle aspiration cytology of the thyroid in routine practice. Diagn Cytopathol 2011;39:81-86.

-24 Baloch ZW, Cibas ES, Clark DP, Layfield LJ, Ljung BM, Bishop-Pitman M, Abati A: The National Cancer Institute Thyroid Fine Needle Aspiration State of the Science Conference: a summation. Cytojournal 2008;5:6

25 Chow LS, Gharib H, Goellner JR, Van Heerden JA: Nondiagnostic thyroid fineneedle aspiration cytology: management dilemmas. Thyroid 2001;11:1147-1151.

26 Guidelines of the Papanicolaou Society of Cytopathology for the examination of fineneedle aspiration specimens from thyroid nodules: the Papanicolaou Society of Cytopathology Task Force on Standards of Practice. Diagn Cytopathol 1996;15:84-89.

-27 Rossi ED, Morassi F, Santeusanio G, Zannoni GF, Fadda G: Thyroid fine-needle aspiration cytology processed by ThinPrep: an additional slide decreased the number of inadequate results. Cytopathology 2010;21:97102.

28 Bellantone R, Lombardi CP, Raffaelli M, Traini E, De Crea C, Rossi ED, Fadda G: Management of cystic or predominantly cystic thyroid nodules: the role of ultrasoundguided fine-needle aspiration biopsy. Thyroid 2004; 14:37-43.

-29 Baloch ZW, LiVolsi VA, Asa SL, Rosai J, Merino MJ, Randolph G, Vielh P, DeMay RM, Sidawy MK, Frable WL: Diagnostic terminology and morphologic criteria for cytologic diagnosis of thyroid lesions: a synopsis of the National Cancer Institute Fine-Needle Aspiration State of the Science Conference. Diagn Cytopathol 2008;36:425-437.

-30 Hasteh F, Pang Y, Pu R, Michael CW: Do we need more than one ThinPrep to obtain adequate cellularity in fine needle aspiration? Diagn Cytopathol 2007;35:740-743.

31 British Thyroid Association: Guidelines for the Management of Thyroid Cancer, ed 2. London, Royal College of Physicians of London, 2007.

-32 Cooper DS, Doherty GM, Haugen BR, Kloos RT, Lee SL, Mandel SJ, Mazzaferri EL, McIver B, Pacini F, Shlumberger M, Sherman SI, Steward DL, Tuttle RM: Revised American Thyroid Association management guidelines for patients with thyroid nodules and differentiated thyroid cancer. Thyroid 2009; 19:1-48.
33 Busseniers AE, Oertel YC: 'Cellular adenomatoid nodules' of the thyroid: review of 219 fine-needle aspirates. Diagn Cytopathol 1993;9:351-354.

34 Tulecke MA, Wang HH: ThinPrep for cytologic evaluation of follicular thyroid lesions: correlation with histologic findings. Diagn Cytopathol 2003;30:7-13.

-35 Yang J, Schnadig V, Logrono R, Wassermann PG: Fine-needle aspiration of thyroid nodules: a study of 4,703 patients with histologic and clinical correlations. Cancer 2007;111: 306-315.

36 MacDonald L, Yazdi HM: Fine needle aspiration biopsy of Hashimoto's thyroiditis: sources of diagnostic error. Acta Cytol 1999; 43:400-406

37 Kumar N, Ray C, Jain S: Aspiration cytology of Hashimoto's thyroiditis in an endemic area. Cytopathology 2002;13:31-39.

38 Das DK: Marginal vacuoles (fire-flare appearance) in fine needle aspiration smears of thyroid lesions: does it represent diffusing out of thyroid hormones at the base of follicular cells? Diagn Cytopathol 2006;34:277283.

39 Anderson SR, Mandel S, LiVolsi VA, Gupta PK, Baloch ZW: Can cytomorphology differentiate between benign nodules and tumors arising in Graves' disease? Diagn Cytopathol 2004;31:64-67.

40 Fadda G, Basolo F, Bondi A, Nardi F, Basolo F, Bussolati G: Cytological classification of thyroid nodules: Proposal of the SIAPECIAP Italian Consensus Working Group. Pathologica 2010;102:405-408.

41 Bronner MP, LiVolsi VA: Oxyphilic (Askenazy/Hürthle cell) tumors of the thyroid: microscopic features predict biologic behavior. Surg Pathol 1988;1:137-150.

42 Carcangiu ML, Bianchi S, Savino D, Voynick IM, Rosai J: Follicular Hürthle cell tumors of the thyroid gland. Cancer 1991;68:19441953.

43 Mete O, Asa SL: Oncocytes, oxyphils, Hürthle, and Askanazy cells: morphologic and molecular features of oncocytic thyroid nodules. Endocr Pathol 2010;21:16-24.

44 Pu RT, Yang J, Wassermann PG, Bhuiya T, Griffith KA, Michael CW: Does Hürthle cell lesion/neoplasm predict malignancy more than follicular lesion/neoplasm on thyroid fine-needle aspiration? Diagn Cytopathol 2006;34:330-334

45 Giorgadze TA, Rossi ED, Fadda G, Gupta PK, LiVolsi VA, Baloch ZW, et al: Does the fineneedle aspiration diagnosis of 'Hürthle cell neoplasm/follicular neoplasm with oncocytic features' denote increased risk of malignancy? Diagn Cytopathol 2004;31:307-312.

46 Nguyen GK, Husain M, Akin MR: Cytodiagnosis of benign and malignant Hürthle cell lesions of the thyroid by fine-needle aspiration biopsy. Diagn Cytopathol 1999;20:261265.
47 Renshaw AA: Hürthle cell carcinoma is a better gold standard than Hürthle cell neoplasm for thyroid fine-needle aspirates: defining more consistent and specific cytologic criteria. Cancer 2002;96;261-266.

48 Elliott DD, Pitman MB, Bloom L, Faquin WC: Fine-needle aspiration biopsy of Hürthle cell lesions of the thyroid gland: a cytomorphologic study of 139 cases with statistical analysis. Cancer 2006;108:102-109.

49 Montone KT, Baloch ZW, LiVolsi VA: The thyroid Hürthle (oncocytic) cells and its associated pathologic conditions: a surgical pathology and cytopathology review. Arch Pathol Lab Med 2008;8:1241-1250.

50 Sanchez N, Sevaggi SM: Utility of cell block in the diagnosis of thyroid aspirates. Diagn Cytopathol 2006;34:89-92.

51 Ravetto C, Colombo L, Dottorini ME: Usefulness of fine-needle aspiration in the diagnosis of thyroid carcinoma: a retrospective study in 37,895 patients. Cancer 2000;90: 357-363.

$52 \mathrm{Lu} \mathrm{L}, \mathrm{Gu}$ F, Dai WX: Clinical and pathological features of Riedel's thyroiditis. Chin Med Sci J 2010;25:129-134.

53 Malle D, Valeri RM, Pazaitou-Panajiotou K, Kiziridou A, Vainas I, Destouni C: Use of thin-layer technique in thyroid fine needle aspiration. Acta Cytol 2006;50:23-27.

-54 Cavaliere A, Colella R, Puxeddu E: Fine needle aspiration cytology of thyroid nodules: convetional vs. thin layer cytology. J Endocrinol Invest 2008;31:303-308.

- 55 Rossi ED, Raffaelli M, Mulè A, Zannoni GF, Pontecorvi A, Santeusanio G, Minimo C, Fadda G: Relevance of immunocytochemistry on thin-layer cytology in thyroid lesions suspicious for medullary carcinoma: a casecontrol study. Appl Immunohistochem Mol Morphol 2008;16:548-553.

-56 Papi G, Corsello SM, Cioni K, Corrado S, Scaltriti L: Value of routine measurement of serum calcitonin concentrations in patients with nodular thyroid disease: a multicenter study. J Endocrinol Invest 2006;29:427-437.

57 Colasacco C, Mount S, Leiman G: Documentation of immunocytochemistry controls in the cytopathologic literature: a meta-analysis of 100 journal articles. Diagn Cytopathol 2011;39:245-250.

- 58 Pazaitou-Panayiotou K, Mygdakos N, Boglou $\mathrm{K}$, et al: The immunocytochemistry is a valuable tool in the diagnosis of papillary thyroid cancer in FNAs using liquid-based cytology. J Oncol 2010;2010:963926.

59 Leung SW, Bedard YC: Immunocytochemical staining on ThinPrep processed smears. Mod Pathol 1996;9:304-306.

-60 Dabbs D, Abendroth CS, Grenko RT, Wang $\mathrm{X}$, Radcliffe GE: Immunocytochemistry on the thin prep processor. Diagn Cytopathol 1997; 17:388-392.

61 Grubbs EC, Rich TA, Li G: Recent advances in thyroid cancer. Curr Probl Surg 2008;45: 156-250. 
62 Schmitt FC, Longatto-Filho A, Valent A: Molecular techniques in cytopathology practice. J Clin Pathol 2008;61:258-267.

63 Xing M: BRAF mutation in papillary thyroid cancer: pathogenic role, molecular bases, and clinical implications. Endocr Rev 2007; 28:742-762.

64 Zhang Y, Fraser JL, Wang HH: Morphologic predictors of papillary carcinoma on fineneedle aspiration of thyroid with ThinPrep preparations. Diagn Cytopathol 2001;24: 378-383.

65 Nikiforov YE, Steward DL, Robinson-Smith TM: Molecular testing for mutations in improving the fine-needle aspiration diagnosis of thyroid nodules. J Clin Endocrinol Metab 2009;94:2092-2098.

-66 Nikiforova MN, Nikiforov Y: Molecular diagnostics and predictors in thyroid cancer. Thyroid 2009;19:1351-1361.

-67 Soares P, Trovisco V, Rocha AS, Lima J, Castro P, Preto A, Maximo V, Botelho T, Seruca $\mathrm{R}$, Sobrinho-Simoes M: BRAF mutations and RET/PTC rearrangements are alternative events in the ethiopathogenesis of PTC. Oncogene 2003;22:4578-4580.
68 Cheung CC, Carydis B, Ezzat S: Analysis of ret/PTC gene rearrangements refines the fine needle aspiration diagnosis of thyroid cancer. J Clin Endocrinol Metab 2001;86: 2187-2190.

69 Musholt TJ, Fottner C, Weber MM: Detection of papillary carcinoma by analysis of BRAF and RET/PTC1 mutations in fineneedle aspiration biopsies of thyroid nodules. World J Surg 2010;2:2595-2603.

70 Eszlinger M, Paschke R: Molecular fine-needle aspiration biopsy diagnosis of thyroid nodules by tumor specific mutations and gene expression patterns. Mol Cell Endocrinol 2010;322:29-37.

71 Park SY, Park YJ, Lee YJ, et al: Analysis of differential BRAF(V600E) mutational status in multifocal papillary thyroid carcinoma: evidence of independent clonal origin in distinct tumor foci. Cancer 2006;107:18311838 .
72 Soares P, Trovisco V, Rocha AS, Lima J, Castro P, Preto A, Maximo V, Botelho T, Seruca $\mathrm{R}$, Sobrinho-Simoes M: BRAF mutations typical of papillary thyroid carcinoma are more frequently detected in undifferentiated than in insular and insular-like poorly differentiated carcinomas. Virchows Arch 2004;444:572-576.

73 Ohori NP, Nikiforova MN, Schoedel KE: Contribution of molecular testing to thyroid fine-needle aspiration cytology of 'follicular lesion of undetermined significance/atypia of undetermined significance'. Cancer Cytopathol 2010;118:17-23.

74 Moses W, Weng J, Sansano I: Molecular testing for somatic mutations improves the accuracy of thyroid fine-needle aspiration biopsy. World J Surg 2010;34:2589-2594.

75 Saleh HA, Hammoud J, Zakaria R, Khan AZ: Comparison of Thin-Prep and cell block preparation for the evaluation of thyroid epithelial lesions on fine needle aspiration biopsy. Cytojournal 2008;25:3.

76 Fadda G, Rossi ED, Martini M, Lombardi CP, Zannoni GF, Vellone VG, Ferrara AM, Pontecorvi A, Rindi G: BRAF mutation (V600E) in papillary carcinoma identified on LBC processed thyroid aspiration biopsies. Mod Pathol 2011;24:89A. 